\title{
Faculty Training And Development Practices In Distance Education To Achieve High Performance Through Extraordinary Teaching
}

\author{
Dr. Bahaudin Mujtaba, (E-mail: Mujtaba@nova.edu), Nova Southeastern University
}

\begin{abstract}
Developing and training faculty members to integrate cyberspace technology into the classroom for student learning is basically a necessity in today's competitive world of education, but many educators fear or resist it due to lack of effective training. As such, administrators should focus on the effective development, training, and retaining of qualified educators to teach in various distance learning modalities (online, on-ground, and blended formats) using cyberspace technology while focusing on effectively achieving learning outcomes. An emersion model of training used for "training-the-trainers" in the corporate arena as well as for faculty development is presented for application and benchmarking. Personal experiences and best practices gleaned from different universities (business programs using cutting edge technologies) and corporate computer-based training are discussed. Also, best practices and suggestions for effective faculty compensation and teaching load in distance education are explored. Furthermore, administrators must ask for participation and interaction of experienced educators in order to glean and highlight their successes as well as challenges they face currently in serving the needs of diverse student populations in distance education. Both means and processes for effective faculty development and training in a just-in-time basis with least cost and expenditure should be implemented by the administration.
\end{abstract}

Foundational Training and Development Practices in Adult Education

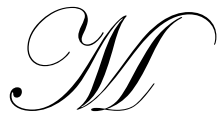

any traditional and non-traditional universities have integrated online education into their delivery systems to enhance their offerings and student learning. Many of the universities such as Carnegie-Mellon, London School of Economics and Political Science, Columbia University, and University of Chicago have created partnerships with suppliers such as UNext to aid with their online initiatives in course development (Barnes \& Blackwell, 2004). Some of the for-profit institutions that are successfully using commonly available platforms in cyberspace technology include Walden, Kaplan University, University of Phoenix, Capella University, Jones International University, and Unexus just to name a few. Some of Nova Southeastern University's internal schools have used their own custom-built platforms such as their Huizenga School of Business and Entrepreneurship which used e-University while their undergraduate programs used the standard WebCT package. Other universities and colleges may be using software and courseware programs such as Outlook Express, Blackboard CourseInfo, Web Courses-in-a-Box, TopClass, WebMentor, Lotus LearningSpace, Groupware, and/or many other user-friendly packages entering the market. Hearing about such new software programs and their usage can be scary to traditional faculty members who have been effectively teaching classes in a face-to-face format without the integration of advanced technology. As such, many of the aforementioned schools have developed standardized training programs to make sure their faculty members are trained, developed and successfully using cyberspace technologies as they compete to survive and hopefully capture a fraction of the market share in education using online modalities. Peter Drucker, the father of modern management, said Universities will not survive if they do not adjust to distance learning (Gubernick \& Ebeling, 1997). Drucker also said that the future is outside the 
traditional classrooms and the traditional campuses. Training and development programs may vary in terms of skill and pedagogy but many schools are creating programs that use online training as its basis, due to its low cost and flexibility of scheduling, in educating qualified faculty members throughout the globe so long as they have access to the internet. Distance education and distance learning are realities of life and educators should embrace it in order to create a healthy learning environment for diverse students. Educators must use distance education technology to enhance their offerings. However, they need continuous training and development opportunities to keep up with the changes in the application of technology.

Developing and educating faculty members are today's necessities as new technology to enhance learning is being introduced periodically so everyone can stay updated and skilled in their usage. A major element of effectively assisting faculty members develop is to understand the nature of how adults learn best and then create an environment and processes that are conducive to learning effectively. Some administrators may be of the mindset that educators are already developed and they learn by osmosis; as such, they do not require formal development. A colleague in the corporate training world used to say that "people learn differently and facilitators of education are people too." Faculty members, just like other adults, need to be involved in the learning process in order for the learning to be enjoyable, effective and long-term oriented. Just-in-time education, learner participation during the session and interaction are critical to effective facilitation techniques that increase learning and retention with adult learners. A major element of being or becoming an effective educator involves understanding how each group of participants learn best and then integrating activities that best suit their learning styles regardless of teaching modality. Adults are autonomous, self-directed, goal-oriented, relevancy-oriented, and practical since they tend to focus on the aspects of a lesson most useful to them in their work. Furthermore, they have accumulated a foundation of life experiences and knowledge that may include work-related activities, family responsibilities, and previous education. An effective facilitator must remember that, as do all learners, adults need to be shown respect.

While considering the aforementioned characteristics of adult learners, facilitators should acknowledge the wealth of experiences that adults bring with them that can be integrated into the learning modules. These adults should be encouraged to take initiative in their learning and they must become a part of the learning process through effective facilitation by the facilitator and appropriate administrative processes that allow learners to become a part of the learning experience. There are many elements that should be considered with adults in the educational environment and one is that adults are likely to engage in learning activities before, after, or even during any challenges facing them (which are described as "teaching moments or opportunities") and they are likely to engage in learning that promises to help them cope with the transition. Furthermore, adults are concerned about their selfesteem and ego which influences their behavior. Facilitation should respect their dignity and self-esteem concerns. Facilitators must remember that the average adult can effectively focus on a limited number of concepts at a given time. The facilitator or trainer should effectively balance the presentation of new material, discussions, sharing of relevant experiences, and the time allotted. Trainers and facilitators should recognize that adults want their learning to be problem-oriented, personalized and appropriate to their need for direction and personal responsibility.

\section{Pedagogy of Learning and Extraordinary Teaching}

Learning is about the enhancement of one's capacity for effective action both immediately and in the near future. Learning is about building knowledge that brings more joy and opportunities to make better and more valuable contributions to one's field, industry and profession. Knowledge is not just the ownership of information but rather knowledge is one's capacity for effective actions, and the more immediate the need for relevant action the greater the need for learning. Human beings are designed to learn by nature. Each person has the natural drive, capacity and hunger to learn. We have the capacity to create the kinds of jobs we want to be in as well as to create the types of communities and societies in which we want to live. Unfortunately, many ineffective training and development sessions at many institutions do not encourage this because they are and have always been very "controlling"-top officials think and lower level employees act as done in most traditional or centralized organizations. Traditionally in schools, educators lectured and learners memorized to the best of their abilities in order to reproduce correct answers on the examination. This system has not been very effective in our society and it certainly will not be very effective for adult learners that teach others. As such, facilitators must work with each 
individual faculty or groups of faculty members in effectively developing them in the appropriate and timely use of advanced technology in the achievement of course learning outcomes with extraordinary results.

Mahatma Gandhi once said that you should "Learn as if you will live forever, live as if you will die tomorrow." Extraordinary teachers continuously learn and pass on relevant (updated) information to their students. There is an interesting book titled "Extraordinary Teachers: The Essence of Excellent Teaching", by Dr. Frederick Stephenson, Associate Professor of Marketing and Distribution at the University of Georgia's Terry College of Business. The book is basically a compilation of about thirty six papers written by teachers that are considered to be extraordinary and have also received the Josiah Meigs Award for Excellence in Teaching (the highest teaching honor given by the University of Georgia). Throughout the book, six characteristics of extraordinary teachers are discussed. Extraordinary teachers have great passion for their work; they know what to teach, how to teach, and how to improve; they tend to excel at creating exciting classroom environments; they are able to connect exceptionally well with the audience; they challenge learners to reach their full potential; and they usually get extraordinary results using a good variety of skills appropriate to the situation.

Dr. Stephenson went on to mention the applicability of the six characteristics no matter at what level one is teaching. All faculty members should continually demonstrate these characteristics in order to deliver superior value through extraordinary teaching. The objective of faculty development sessions should be to assist educators maintain and develop extraordinary teaching skills. Extraordinary teachers want students to say that "my professor had great passion for the subject area, connected my experience to the learning objectives of the session/course, challenged me to stretch and learn beyond my known abilities, and assisted me in achieving extraordinary outcomes." Michael Jordan, the extraordinarily successful basketball star, said "You have to expect things of yourself before you can do them." The same can be applied to faculty members' teaching styles and expectations as they assess or reflect upon their own current performance in the class and expect higher levels of success with their students in achieving the stated learning outcomes by becoming an extraordinary teacher.

Effective facilitators of learning use innovative strategies to achieve the stated outcomes and they tend to involve students in the learning process (Mujtaba, Preziosi, and Mujtaba, 2004). For example, Dr. Marcia Silver, in her Adulthood and Aging class, in an effort to help the traditional nineteen to twenty-two year old students understand some of the personal and societal difficulties that the elderly experience because of reduction in sensory perceptual abilities asked her students to participate in a simulated sensory loss. Students were given eyeglasses smeared with Vaseline to simulate blurred vision and cataracts, earplugs to simulate loss of hearing, as well as ace bandages, walkers, and canes to experience loss of mobility. As part of the assignment, the "elderly" students are asked to walk along the corridors of the building, climb stairs, buy snacks from nearby vending machines, and sit or stand while encumbered with the various apparatuses. The final component of the experiment asked students to write an essay about the entire experience while integrating academic concepts with practical experiences. While adult learners enjoy being involved in the simulation, such experiments usually accomplish the objectives because the learners are involved in an enjoyable process. Based on the completed essays for her class, the outcomes showed that the class developed empathy and a greater understanding of some of the physical and emotional challenges that face the elderly. Extraordinary teachers, like Dr. Silver, often take care of their learners as they take care of guests when it comes to being responsive to students' collective and individual learning needs as well as their educational goals, while enforcing the university polices with high academic rigor. Seeing adult learners as "stars" and "guests" requires a learner-centered paradigm where the faculty member serves as a "facilitator" in the process rather than a purveyor of information. This facilitation paradigm requires that adult learners become active participants in their roles as "stars" and "guests" in the class. Traditionally speaking, people welcome their guests, call them by their names, take care of their needs, thank them for coming, and, often times invite them back. Perhaps, many of the same concepts can be applied to adult learners as well (welcoming them to the class, calling them by their names, taking care of their individual educational/learning needs, and thanking them for participating qualitatively in each session). Thus, faculty members can welcome adult learners to the class, call them by their names during the sessions, take care of their individual learning needs (academically and connecting with them based on real-world experience), thank them for participating in the classes and submitting quality assignments on time, and by inviting them to (and encouraging them to) continue using their knowledge both academically and practically. Adults should keep in mind that a person who has the knowledge to do something but chooses not to use this knowledge may not 
be much better than a person who does not have the knowledge. Knowledge is not power, nor useful, without effective utilization, application and results.

\section{Faculty Training and Development Practices in Distance Education}

Faculty development and retention is a critical element of a successful institution. Result-oriented faculty members have always been and will continue to be an important and mission critical asset to any University as they have the most important job in the world - preparing future leaders of the society! Therefore, one of each educational institution's goals must be to recruit, develop and retain part-time and full-time faculty members with the required skills to effectively compete in the global industry because students seek to learn from them the skills required to compete with the very best in their professions.

As most entrepreneurs know, for many institutions today, the true sustainable advantage comes from outinnovating the competition in a timely manner. Someone said that it matters not which particular organization stays alive, rather, it's only essential that competition among them is fierce yet fair and eventually the fittest may survive. Therefore, educational institutions cannot survive nor prosper without extraordinary faculty members who can be innovative and globally competitive. So, all institutions need to have a standardized process to consciously recruit, hire, orient, develop, and retain extraordinary faculty members for all education modalities. Having a standardized faculty development process is even more critical for institutions involved in distance learning. The faculty development process and model presented here is one way of going about documenting and standardizing the process both for development and accreditation purposes.

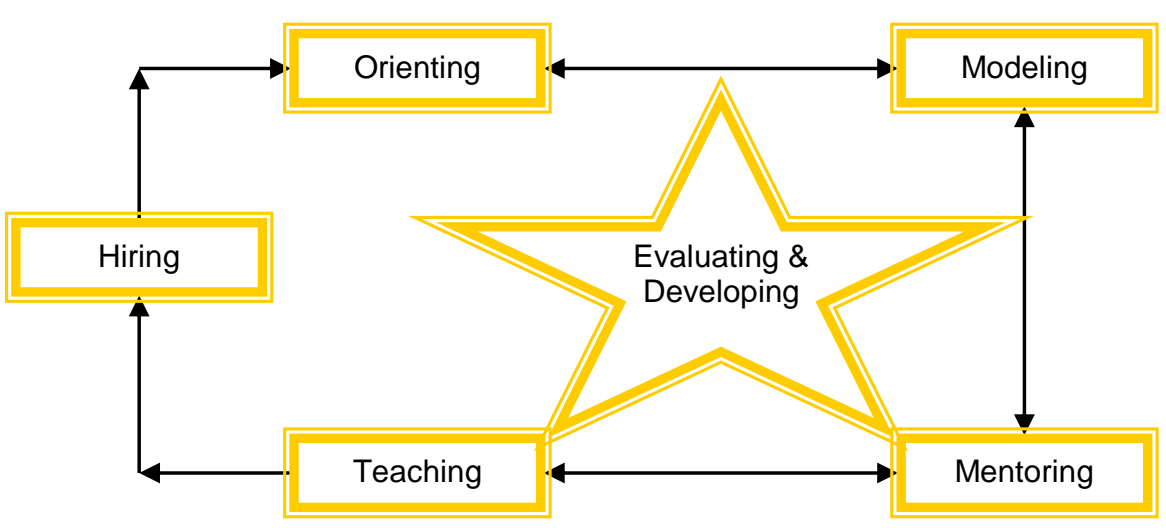

Best practices and specific details on each step of the model should be designed as per the needs and situational variables of the institution. Benchmarking can take place by speaking with others involved in distance education and those who have years of experience in academic administration using cyberspace technology. Some general considerations for each of the steps in the model may include but are not limited to the following:

* Hiring

$>$ Considering academic credentials

$>$ Professional experience and teaching flexibility

* Orienting

$>$ Education about facilitating learning

* Modeling

$>$ Pedagogy of adult education

$>$ The faculty experiences learning as a student.

$>$ The faculty observes and teaches a mock class.

* Mentoring

$>$ Evaluating and enhancing lesson plans, lectures, and activities.

$>$ Making sure the content is being facilitated to achieve learning outcomes 
* Teaching

$>$ On-going training and development is offered on a just-in-time basis.

$>$ Faculty is monitored to make sure technology is being used effectively to achieve learning outcomes.

* Evaluating \& Developing

$>$ Evaluation should be an ongoing process

$>$ Development should be focused on student learning

Faculty members wishing to teach online should become online students first and learn the pedagogy of online education along with the school's electronic platform. This immersion model of training has been used to train corporate trainers and to develop faculty members in distance education. Understanding its practical application, successes, challenges, and best practices can be of great assistance as a starting place. Some suggestions offered for beginning online faculty members are:

* Learn and understand the mechanics of how online environment of education works.

- Collect best practices and tips for beginning online faculty members to be effective in their initial online experience.

* Discover what learning strategies work best for teaching, understanding and learning the course material.

- Know how to best engage students, keep them interested and on track to achieve course and curriculum learning outcomes.

* Learn how to best manage time to adequately show presence on the discussion board. The minimum number of times faculty members should $\log$ on to their courses each week must be clarified for a foundational standard and consistency.

* $\quad$ Find out how to best manage discussion threads with large quantities of comments.

There are many best practices that new online faculty members can absorb, perhaps through osmosis, and benefit from as they observe an actual class facilitated by an experienced online educator. Furthermore, online administrators and facilitators should discuss and integrate some or all of the following suggestions for online courses:

* Use the basic technology available to everyone in the market and the sophistication of technology requirements should be kept simple or to the lowest common denominator (Barnes and Blackwell, 2004).

* Software, content links and "self help" training sessions should be regularly updated and made available asynchronously. Technical support experts should be available for online learners and educators seven days a week and 24 hours each day as online education is about learning at one's own pace and time.

* Ask for contributions from faculty members, staff and students on ways to improve the system. Involve everyone that is impacted by the process, hear their concerns and, when possible, integrate their suggestions.

* Rules, policies and training material should be formal and standardized. However, the training and facilitation of the content should be personalized, to the extent possible, based on learning styles and the individual needs of each learner.

* For best results and when possible, effectively and appropriately use both asynchronous and synchronous formats depending on the learning objectives. Because adults like to learn at their own pace and time, synchronized online learning and assessment requirements should be limited to the bare necessities when used.

* Communicate regularly with online faculty members and students about the technology usage, software updates, and overall program objectives. Also, questions submitted through emails and bulletin board postings should be answered within a 24-hour period or as determined by the needs of learners and the availability of resources.

* Create a standardized mechanism for documentation of feedback and development for each learner. This helps the faculty member to effectively observe, monitor, evaluate, and develop the progress of each learner. Similarly, such a process can greatly assist the learner understand his/her learning gap and do what is possible to close the gap between where he/she is and where he/she intends to go at the end of each term or module. 
* Compensate facilitators fairly while considering the amount of work that goes into preparing for the class before its beginning, interaction time and content preparation while the class is in session (asynchronously or synchronously), and communication time or follow up needed with learners once the session has ended.

- Periodically measure and assess the actual learning to make sure it matches the intended learning objectives. Online groups can be compared with each other or with groups that meet face-to-face learning the same content through similar facilitation. Statistical analysis can be performed for data over time and relevant conclusions can be drawn. Make appropriate adjustments as needed.

\section{Online Teaching and Learning Techniques}

Pedagogy in online education requires the application of learning techniques and facilitation that works in the on-ground environment using different mediums or modalities of delivery. For example, students take tests to show their understanding of the concepts, theories, cause and effect relationships, etc. to the faculty and the institution. In the traditional classroom, students can complete their exams using a computer, the paper and pencil format and/or through oral examinations. Online faculty members can do the same things using online mediums both asynchronously and synchronously using proctored formats when needed. Computerized cameras and teleconferencing technology has made the impossible possible and yesterday's vision into today' reality for online students and faculty.

For effective learning of students, online faculty members should be involved in class interactions each week (four-five days per week) and respond to questions within 48 hours since the new generation of learners are being conditioned to expect feedback instantly through the widespread use of "instant messaging" software. If one is not able to adhere to such simple guidelines by providing feedback to students in a timely manner due to other responsibilities, then one should not teach in the online modality. Online classes should achieve the same outcome as on-ground courses using online modality. Often students will spend more time on online courses than they do at the on-ground courses because there is no face-to-face interaction. Generally speaking, online courses have more assignments submitted than on-ground courses. This also means more work for the faculty. Online education is and should be convenient (as is the case with evening and weekend programs) but should not be lenient with its academic rigor. The following are some general guidelines and best practices for online educators.

* All assignments should be posted with clear directions, expectations and due dates. The evaluation methodology should be mentioned to students as well.

* Post a comprehensive lecturette each week for students the day before the week starts. The lectures should be related to the assigned readings and the faculty member's personal experiences and thoughts about the material. The lecturettes should not just summarize the assigned textbook and article readings but it should offer more examples and personal experience with the literature. Faculty members may supplement weekly lecturettes with PowerPoint slides and links to relevant online articles, websites and newsgroups. One should make sure students know that they are to read their assigned textbook reading since lecturettes are supplementary material to reinforce and/or enhance their learning.

* Discussion Board should be monitored every other day (if not every day) and used by the faculty member in all classes. Faculty members should post and respond to students' postings regularly to monitor learning, guide interactions toward course objectives, to show presence, and to encourage effective participation. Furthermore, faculty members should post appropriate cases and topics to reinforce the weekly assignments and objectives when needed and appropriate. One should be involved and post something related to the weekly objectives of the class at least four to five days each week to raise student contributions, interest in the content and learning. One can post relevant weekly questions, dilemmas, problems, cases, etc. to achieve the stated objectives of the course and to involve students in the interaction each week.

* Holding synchronized chat sessions is a good idea to either clarify content or to test everyone's comprehension of material on a real time basis. For example, Huizenga School encourages that each online faculty hold several chat sessions during the term with students and require students to attend at least two of the assigned chat sessions by awarding points (which can be a small portion of the participation grade). Attendance to two chat sessions should be mandatory; while, attendance to the remaining chat sessions 
should be encouraged by linking them to awarding of weekly participation points. Chat sessions can be about one hour and they should be conducted at reasonable times to accommodate working adults. Determine chat session times and dates during the first week of class to accommodate as many of the students' schedules as possible. Chat sessions should not be confused with online office hours since effective chat sessions can be used to evaluate students' comprehension of the material by asking them direct questions related to the content of each week's objectives. Although, having online office hours is not a bad idea either to answer any questions for students. Online office hours often range from 10-15 minutes at a specified time each week (or day) in case students have questions about course content, assignments, or team activities.

* Presence of the faculty and requesting relevant contributions from students to specific assignments (discussion questions, case studies, article summaries, debates, etc.) each week will increase participation, interaction, student reflection, the quality of learning in each class, and the program effectiveness. Again, the faculty member should be involved with the students each week in the online class at least four to five days each week to facilitate the learning objectives.

* Quality feedback for all assignments should be provided to students within one week of original assignment due date (or submission), if not earlier. Timely and quality feedback is critical to student learning and progressive improvement.

* Participation feedback/grade should be given each week (if grades are awarded on a weekly basis) or at mid-term and final week (if participation points are cumulative). If student grades are low because of lack of participation in the online classroom and nothing was communicated to them in a timely manner then they would not be aware that they needed to improve. So, proper feedback in a timely manner must be provided to students starting at the end of week one of the course!

* Individual email correspondence should be reserved for personal student issues and course feedback. All other course related discussions should be conducted in the course newsgroup and/or course bulletin board.

* Deadlines and submission policies must be consistently applied and enforced to all students. All assignments must be received by the course deadline and grades should be awarded appropriately. Offering students extended time to complete assignments without a good reason (exceptional circumstances) is not a good practice in the online world either. Students need to discipline themselves to complete their work on time. Also, providing extra credit opportunities for students may not be a good practice as it conditions some of them to not worry about completing quality assignments in a structured manner which is very important for all students, especially in the online environment.

An important aspect of online education is the effective evaluation and feedback process that is ongoing for both students and faculty members. Online faculty members, especially those who are just starting to teach online, need quality feedback in order for them to improve their facilitation skills.

\section{Online Faculty Peer Review: Exploring an Actual Model}

As we all know, timely and constructive feedback benefits the faculty, students and the institution itself; in that regard, a peer review can be one of the most positive features of the Online teaching experience. The review program should be designed to provide online faculty members with personalized feedback, based on performance, as observed by experienced online faculty leaders/reviewers. The feedback should be designed to help faculty members in their continued development and to enhance their online skills in order to provide the finest educational experience for students. Let us discuss one example from the University of Phoenix's (UofP) Peer Review program, where each new online faculty member can expect to be reviewed after the fourth course, followed by annual reviews on the anniversary of the first review.

The peer reviews at UofP are randomly scheduled using experienced and certified reviewers. Based on the success of the Peer Review program, it is hoped that every online faculty will continue to welcome and embrace such important efforts. The following are the key elements of the Peer Review process used at the UofP and how the Peer Review program actually operated during 2003 and it is continuing into the 2004 academic year. 
* Each faculty member is reviewed every 12 months. All new instructors receive an automatic Peer Review following the fourth completed online course; subsequent reviews are scheduled on the anniversary of the first review.

* After being identified by the selection system, the faculty member is notified of the upcoming Peer Review on the first day of the last week of the selected course. Upon notification, the faculty is asked to place samples of weekly student evaluation feedback notes and graded assignment feedback into a designated newsgroup. Since timely and relevant student feedback is such a critical component of online education, it is critical that reviewers have access to this essential information. Of course, placing the feedback in the designated newsgroup helps the reviewers to avoid disturbing the faculty members as they usually have a pretty busy schedule.

* The Director of Training \& Development has overall responsibility for Faculty Candidate Training, Mentoring, Workshop Facilitation, Course Development, Faculty Leadership and Peer Reviews. Each of these areas is staffed by some of the most experienced and respected Training and Development staff, who are also seasoned, full-time faculty members. The Peer Review Team and their excellent staff are dedicated to making this a valuable and rewarding experience for the entire Online Faculty. Their mission is basically to help each faculty become an extraordinary online educator.

* All reviewers are faculty peers and colleagues, selected from among the most experienced and successful Online instructors. Each has undergone rigorous selection and training for this assignment and the reviewer will also be an experienced Faculty Trainer, as well as an approved Mentor and Workshop Facilitator. The reviewers not only represent the best of the best, but they also consider this opportunity to assist their fellow facilitators both an honor and a privilege.

* Following the end of the course, the faculty that is going through the review process, will have seven days in which to post the required assignment feedback and weekly grade summaries to the designated newsgroup. At this time, the reviewer will be granted access to all the class newsgroups. During the next week, s/he will conduct the review of the entire course using a standardized format - the Peer Review form was carefully developed with the assistance of members of the online faculty team. Following submittal of the form, the Peer Review team will analyze the results and make appropriate notifications and follow-up contact. Selected faculty members may also receive an electronic certificate with the school's logo and words of appreciation for excellent teaching.

* In order to avoid any possible bias or distraction, Peer Reviewers do not directly interact with faculty members. All notifications, feedback and follow up are handled by members of the Peer Review team. Since members of this team have access to all the answers, this provides the faculty with 'one-stop shopping', in the event s/he has questions or concerns about the review.

* After completed forms are reviewed and processed by the Peer Review team, the faculty will receive feedback within just a few weeks following the end of the reviewed class. This feedback also describes any areas of reviewer concern, as well as suggestions and coaching ideas, as needed.

* A chief reason for the Peer Review is to identify and reinforce excellence in the facilitation process; however, should the reviewer discover an area of facilitation that needs attention, the faculty will be offered whatever immediate assistance or follow-up action is necessary, to help him/her bring everything within Online facilitation standards. Actions could include coaching and self correction, attending a faculty refresher workshop or, in some cases, referring the situation to an Online Instructional Specialist for more detailed follow up and assistance.

* The Peer Review program is designed to ensure that all online instruction is in accordance with established faculty standards and best practices. In addition to the rigorous faculty training and mentorship materials, their Faculty Handbook is an excellent source of information on standard expectations. In addition, the faculty always has access to special resources designed to assist him/her in remaining current in these areas. In addition to the Faculty Handbook, rules about classroom facilitation and participation, student feedback, grading practices, course materials, instructor availability, or any other required practices are all available online in their website. Also, a copy of the standard Peer Review form is usually sent with the Peer Review notification message to the faculty at the time his/her review is scheduled.

* As specified in the Faculty Handbook and faculty contract, the University reserves the right to monitor faculty performance, in order to ensure that the highest quality education is provided in the virtual classrooms. However, the campus routinely schedules only one annual faculty Peer Review. 
This Peer Review model seems to work very effectively as it provides timely feedback for educators and shares best practices with them to enhance their repertoire of teaching skills. The following are a sample of actual feedback from faculty members who have gone through the Peer Review process during 2003:

- This type of comprehensive report, suggestions and coaching is most helpful. I find it to be highly valuable as it gives me incentive to enhance my approach which will bring added excellence to my materials and facilitation. This will positively influence my future classes.

* I would be remiss not to take this opportunity to say thank you for the recent Peer Review, and the constructive feedback provided thereto. It has been my observation, as a new faculty, that there is always someone available to help you learn, progress and achieve your underlying goal - which is to provide the highest possible level of facilitation for the students who attend this university.

* Thank you so much for the review of my performance. I thought the reviewer was accurate, thorough, and kind. The suggested changes and improvements will be implemented immediately. I am captivated by this teaching modality, and I want to become better and better so I can best serve my students and the University. Thank you again!

* Thank you for the feedback, this helps me focus on the areas I need to improve. I have already started to adapt my materials and approach accordingly before beginning my next course. Please thank my reviewer for the valuable feedback and for continued advice as I update my materials.

* I know we all get a bit off the center line as time goes by, and we don't always recognize the slight off course track we are on from that original straight and narrow. I appreciated the comments which were made and received as constructive suggestions to improve the delivery of product and services.

* I really appreciate all of your comments and suggestions. I am about to begin teaching another two classes and I will do my best to implement your suggestions immediately. This is a great help getting a handle on how I am doing as a faculty member and it also helps me focus my efforts as I prepare for future classes.

* I just wanted to say thanks for such a supportive and positive experience! I am adding all the suggestions with each class and they are helping me to ensure the clarity needed for assignments, due dates and such. I was concerned about this since I had a couple of difficult students but the reviewer was very understanding and supportive.

* I appreciate the feedback, and I cannot tell you how much the strokes are all appreciated. It really makes me feel all the time I spend with my students and providing feedback is all worthwhile!

* Thanks again! I want to be a GREAT facilitator therefore I appreciate the feedback, and see it as a great gift.

The comments from faculty members that have gone through the process are very positive and they appreciate having such a standardized process for personal development and improvement. Integrated with effective development programs should be appropriate policies regarding teaching loads and compensation methods for online educators. Most traditional schools that are teaching oriented (as opposed to research orientation) tend to have about 20-30 students in the masters programs for on-ground courses and a teaching load of four courses per term seems normal when no other expectations are placed upon the faculty. However, many traditional schools have graduate assistants that help faculty members in course preparation, teaching, and examinations. However, because online education requires continuous and daily asynchronous interaction through bulletin board, chat sessions, assignment feedback, lectures, etc. with faculty (and not graduate students) it may be extremely challenging to teach four courses effectively for first time online faculty members when there are 30 students in each section. This may even be more challenging for the first couple of years when an institution is just beginning to offer and teach online courses. In such cases, institutions should reduce teaching loads because there is a huge learning curve for both faculty members and technical administrators in resolving day-to-day operational challenges while attempting to ensure learning of students is not hindered. Overall, institutions should limit the size of their courses with regard to enrollment based on such variables as the experience of the faculty, the number of technical administrators who can help students and faculty, the comfort level of beginning online students, the daily or weekly requirements for online interaction, the software availability for exams and quizzes, and other relevant considerations.

Also, faculty members who teach online may not appear to physically be in their offices often if they are using their home computers to access class and as such may not appear to be very busy teaching. While most people 
know that appearances can be deceiving, it is certainly true in the case of online educators since effective online faculty members are really teaching twenty four hours each day. Their online classes begin on the first day of the term, they continue every hour of every day/night, and finally classes end once grades are submitted. So, there is no break for online faculty even when they are on vacation classes continue and learning objectives are being achieved with and through students. The main point here is not to overload online faculty members with too many students in each section of their course; otherwise, quality will suffer. The enrollment in each course should be limited to a manageable number that provides a good diversity of ideas and a number that is conducive to effective learning and timely feedback from faculty. It is strongly recommended that experienced faculty members' input be considered and integrated in determining the appropriate size of online classes. Most faculty members do not want small size classes since they do not offer much student diversity but too many students in a course may make it very difficult to facilitate the learning objectives effectively.

Institutions should create and design a fair compensation strategy for those faculty members who have more students in their classes than the average course enrollment. Institutions should also discuss and create effective criteria for fairly compensating faculty members for developing or updating lecture notes, exercises, cases, and other teaching tools for the online environment when such tools are made available for others to use. Intellectual property issues and concerns should be addressed and policies should be created according to the specific rules of the institution so there is clarity before asking faculty members to devote time into developing lectures that will be made available for others teaching the same course.

\section{Blended Modalities of Education}

Blended moralities of education and distance learning have existed for many decades. For example, Nova Southeastern University has offered blended forms of courses and programs through distance learning since the 1970 's. In the late 1980's and early 1990's doctoral students were using email to communicate with faculty members and then attended on-ground classes on monthly basis for two full days each month or for six consecutive days through "national clusters" in Fort Lauderdale, Florida at the Main Campus. During the 48 face-to-face contact hours, faculty members could facilitate learning of the concepts through exercises or lectures and students could learn the material interactively with their peers. In the mean time, student groups could communicate with each other or with the faculty via email to prepare their assignments, conduct interviews and submit assignments for feedback and evaluation. Today, more sophisticated technologies are available to enhance such distance modes of learning while keeping the face-to-face aspect of education.

Today, online education is also making effective use of blended modalities to enhance student learning. Huizenga School started a cluster of MBA students in Manaus, Brazil in 1998 using a "Hybrid" form of distance education. Students would start their courses using online modality and then the faculty members would travel to Brazil to conduct classes with students for 24 face-to-face contact hours. The on-ground format allowed lectures, exercises, student presentations, and proctored examination. Such hybrid forms of distance education require experienced online and on-ground faculty members. Another version that the Huizenga School introduced again in 2003 was the "Hybrid MBA Program" which allows students and faculty members to meet face-to-face for six hours at the beginning of the term and then classes are conducted online for about one month. Once again, faculty members and students meet face-to-face for six hours in the middle of the term. Then, classes are held online for another month and students finally meet face-to-face for another six hours at the end of the semester.

University of Phoenix implemented a similar program in 2001 called "Flexnet." Students enrolled in the Flexnet Program would meet for four hours face-to-face at the outset of each course and then again for four hours at the conclusion of the course. The weeks in between would be conducted using online modality and requirements. The face-to-face contact hours are used for exercises, lectures, face-to-face teamwork, presentations, examinations, etc. and online formats can do pretty much the same things depending on the course and preferences of the faculty. However, the on-ground sessions seem to fit best for presentations and proctored examinations since most faculty members feel more comfortable assessing students using traditional means. 


\section{Learner Perspective: Getting to Know the Online Faculty \& Learning Styles}

Understanding one's natural or best learning style and trying to adapt other effective learning styles is a necessity toward good and quick learning for time-impoverished working adults that are going to school either in the evenings, weekends or online. A discussion with regards to understanding and becoming familiarized with online teacher's lecture style should be explored. So, the question is: how do students get used to and/or familiar with another person's style in the on-line world of education? Yes, most students will tend to have the same kind of online platform, syllabus outline, weekly discussions, and similar grading criteria for most of their courses in the program. However, the faculty members vary and that by itself will make everything else different. Some schools such as Nova Southeastern University and University of Phoenix do have a standardized process to make the format easier for online students. This is not necessarily the case in all schools, especially schools catering to traditional students, since some schools provide much more freedom for faculty to determine what works best for his or her classes. In those cases, the student has much work each term to get used to new styles, new requirements, and new technologies. While there may be much consistency in online programs, some faculty members are very advanced in online education/protocols and may very well be using advanced cyberspace technologies to enhance the learning process. So, in such cases, students will have to be able to adjust quickly to new methods. So, the challenge still remains, how do students bridge the on-line style gap between one instructor and the next in their progression of classes toward graduation?

That is a very good question and getting to know the faculty is critical to successfully completing assignments. One suggestion would be to get to know the faculty's syllabus and then see how s/he approaches the learning outcomes each week through lectures and assigned readings (students can see the faculty's first week lecture and compare with learning objectives for the first week of the course). In some courses, faculty members may put more stock on students reading the assigned textbooks/articles and some of their lectures will be short and to the point since each course may have one or more specific textbook(s) for that topic. In other courses, textbooks are tools that can and should be used throughout the course and research process but faculty members may provide more detailed lectures or articles for weekly readings.

For the past decade, online services have been conquering the education and training market like there is no tomorrow, and we see that consumers all over the world are throwing themselves over their keyboards. Why? We know that customer service is best delivered face to face otherwise it seems to be a bit mechanical or automated, but then again it is all about convenience. What this means is that communication has its routes and forms, adaptation on the other hand is only a matter of time. Fetching the style in writings can never be simple in accordance to the time span of electronics that we have been encountering lately. Emoticons are used in delivering messages whether with a smile, frown or cry... words talk and eyes listen! Typed or written words express what encounters a human being from the inside (emotions) and the outside (facial expressions) and yet it can best be used to communicate on a professional basis according to the purpose of its use. So in the case of online students, communicating with an online instructor and getting to know him/her without seeing the person and what s/he has to deliver all lies in his/her words and way of typing them and how fast they can penetrate thoughts rather than telling or dictating to students!

The following are actual student responses to surveys conducted in 2003 with forty online graduate students in terms of their best practices in adapting to the online learning world and the faculty members style of facilitation.

* Gapping the style differences between instructors online is no different than on campus style learning. I remember when in a physical college, I had to become accustomed to 4 different instructors in 4 different classes in the same quarter. I actually think that it is easier to acclimate to an on-line instructor because it is only one or two classes at a time for most adult students. However, being flexible and not having any preconceived notions of how class should be will help smooth out the transition between classes and instructors. 
So, adapting to an instructor's teacher style is no different from a physical classroom than an online classroom. While at the undergraduate program, I took between 12- 18 hours a semester and each instructor was different, from their lecture style, how they presented materials, their tests, and how much time they allotted to assist students outside of the classroom. For instance some teachers lectured in class, and were not available outside of class. You had three tests and a final and that was your grade. If you got behind or needed assistance then you needed to find someone in class to work with, and/or get a tutor. Other teachers held regular office hours and assigned homework that was gone over during class, with questions being asked as you went over the assignments.

One major difference between the online and physical classroom would be that with a physical classroom you had a set time with the instructor. Online you do not, you just have to post your thoughts, ideas, questions and wait for a response. The same goes for the team assignments, you do not set up a time to physically meet to work on your team project. The bottom line was you had to get used to the style of the teacher and adapt to the changes you experienced from one classroom to the next. It is beneficial that as an adult student I probably will only take one class at a time, allowing me to focus on one instructor's style at a time.

* I think in the online world of education the hardest part is finding time rather than anything else. The other element I have noticed with online is that one needs to read everything because it is all written on a piece of paper and if you miss something you are doomed. I was amazed when I first had to read the syllabus then the lectures, then the electronic textbook, and then the daily postings. As an online student, you wake up, go to sleep and think ok, what day is it today? What is due and when is constantly on ones mind since the online classes go so fast. On the other hand it is nice not to have to get in the car and drive for an hour, try to find a parking space and rush into class, sit for 2 hours minimum and then drive another hour to get home. A total of 4 hours of class and driving it would be for me never mind the exhaustion. I think it all comes down to preference of learning and style.

* While I was reading the first lecturette for the online graduate course, I could not help to think that undergrad would have been a better learning experience if I could have taken some courses online. In undergrad, I participated in two varsity sports that required travel almost every week, therefore I missed one quarter of all lectures. I do believe that getting to know some professors on a personal and social level enhanced my development as a student and a person. Some lectures and professors I wish I had missed. I guess what I am getting at is that each faculty member is going to use his or her own method of teaching. Some I will find value, some I will not. My plan is to go into each online class as if it was a new client. Some become great clients, some do not.

* I have taken close to 20 online classes and invariably there will be differences with instructors. Many of the basics are the same from class to class. There is freedom given to the faculty in terms of when the assignments are due and to which folders. A scan of the syllabus is important to get a 'feel' for the faculty.

* I had the same concerns myself in developing a learning style in regards to online learning. To me, being a recent college graduate, it will take some adjusting to figure out how to plot my path in the online environment. During my undergraduate studies, I never took an online course. I do see that it will not be as easy as the picture that was painted to me by others who were taking online courses. My biggest task will be disciplining myself with time management to complete assigned readings, written assignments, and discussion questions in such a fast and intense pace. I do feel though, through reading everyone's (peers) biographies and responses to discussion questions each week, that I am not the only one with these issues. Through each other's help, I think we will all make it.

* I think adjusting to different teaching styles is part of being a student. Being flexible is the key. We, as adult students taking one or two classes at a time, are somewhat fortunate in the online program because we only have to "master" one or two instructor's style at a time. It is definitely easier than learning 4-5 styles per semester as we had to in the traditional undergraduate program. I had professors whose emphasis was testing while other professors emphasized homework. You just have to figure out what the professor finds important and gear your work accordingly. It was not always easy but it did prepare me for the real world. As a contractor, I have several bosses I report to for different aspects of my job: my company boss wants things as brief and concise as possible, the government person who oversees the helpdesk likes things fluffed up, the parts and software manager is a big procedure person, etc. It is the same game with different 
players. So, the online and on-ground classes both equally prepare students for their future (or current) job responsibilities as they will have to adjust to the learning and communication styles of their colleagues, peers, customers, suppliers, and bosses.

Online students should quickly condition themselves to the platform used by the cyber faculty and adjust to the teacher's requirements. This is very similar to the on-ground platform; however, online modality maybe new to many adult students and they do not yet have the requisite experience with it. As such, faculty members should do what they can to familiarize students with the requirements at the outset of each course. This can eliminate much undue stress, frustration and negative student-faculty evaluations which are traditionally completed toward the end of each course by students.

Many schools have switched the student evaluation of the course and faculty procedures to the online format because of its convenience and timely processing for improvement. The purpose of this new system is to create a paperless student-faculty evaluation process that can be forwarded to faculty members as soon as their course grades are submitted. Also, administrators can take the necessary steps in improving the service for students if needed and appropriate. Often times, administrators send emails to both faculty and students so they can complete the online evaluations. The student completion rate of course evaluation through the university's website or intranets seems to be low for most on-ground and many online courses. In one example during the fall term of 2003 in the undergraduate program having approximately 5,000 students, only $25 \%$ of the student responded. This meant an average of 2 - 8 students (from an average of 20-25) per class completed the evaluation. O-course, the $25 \%$ could be only those students who were either very happy with the class or not pleased at all. So, there is the non-response bias present which must be taken into consideration as well. If you are like most faculty members, you want the feedback from students, because it helps improve or change teaching techniques to enhance the overall goal which is learning. There are other benefits besides improving one's teaching style or techniques. Evaluations help administrators with merit promotions for fulltime faculty, and they may increase the opportunities to teach more classes for part-time faculty. Furthermore, and more importantly, good feedback keeps everyone in touch with the learning environment and the learners by providing timely feedback.

\section{The Stone Soup Legend and the Spirit of Synergy}

The Stone Soup story is one of the best metaphorical examples of the objective of facilitation in the online classroom. In the story, the main character's purpose is to help the community see how they could create something wonderful that would benefit everyone, if they would each just put into the pot what they had to offer. The same holds true for the discussion in the online classroom and online teaching within an institution.

According to the Stone Soup Legend (2003), there existed a tale, handed down from times long ago, of two travelers on a pilgrimage. Hungry and tired from a long day's journey, they come to a small, impoverished, medieval village, where they decide to rest by the side of the road. One of the travelers builds a small fire, upon which he places a large pot, while the other, having drawn water from the town well, fills the pot and places into the vessel a simple stone. As the two men sit by the fire, bringing their "stone soup" to a boil, the local villagers become inquisitive of the curious antics of these strangers. Eventually, several townsfolk decide to investigate the matter and approach the two travelers to engage them in conversation. Shortly thereafter, there is heard the sound of merriment, as the visitors, who turn out to be quite friendly, share their tales of the lands and people they have met throughout their journey and pilgrimage with the local villagers. Finally, a young boy asks the travelers "But why, pray thee, are you boiling a stone?" One of the pilgrims replies, "So we may eat stone soup." "It must be terribly bland!" says an old woman. "But I have a cabbage, which will add some flavor!" "And I, some carrots, which will add color!" says another villager. "Some potatoes!" offers another, until, shortly, by the contribution of a little by many, a hearty stew was made, upon which the entire village and the weary pilgrims dined... and while doing so, shared their tales, talents, and camaraderie throughout the night. The very next day, the travelers (who by now could be called "strangers" no more), continued their journey, leaving the little town, and its people, behind. But the villagers never forgot them, and the lesson they had learned. In fact, during the hardest of times, in such a time as this tale, that little village thrived, because the townsfolk never forgot how to make "stone soup." Such is the legend of the "Stone Soup Story." 
The legend of "stone soup" applies to the education arena as well when the input of everyone is sought, valued, appreciated, and implemented to enhance the process of facilitation and learning. For example, from your own experiences in the classroom, you can reflect upon some of the specific ways that faculty members can get students to contribute to the discussion(s) in a way that will enhance learning of the material and its practical application. In other words, reflect upon discovering the "ingredients" of a dynamic, interactive classroom discussion that illustrates the "Stone Soup Legend"? Think of how other peer faculty members can get involved as well as how adult students can integrate their experience into the discussions. Then, together with colleagues, you can begin "cooking" and effectively facilitate learning in all modalities of adult education.

\section{Summary}

The adult world of education, using blended formats of distance learning delivery, has achieved a special market in the adult world by offering quality educational programs both nationally and internationally at times convenient to students. Through professional faculty members committed to student learning and their ability to combine academic theory with successful practical tools as well as their ability to effectively adjust to the changing educational needs of working professionals, online educators have and can offer great value to their students and their community at large. As such many schools have enjoyed increased enrollment over the past five years due to their quality, convenience, and satisfied stakeholders.

Over twenty-five years ago, when few other institutions proactively considered their students' needs, the distance educators, such as NSU, strove to accommodate working professionals by creating innovative programs to meet the needs of adult students. Today, that tradition continues at the Huizenga School of NSU with better and more innovative teaching features using internet and cyberspace technologies. Online's unique feature has been and continues to be its flexibility to tailoring delivery of educational programs to the particular needs of corporations. Administrators and faculty are keenly attuned to the complicated demands placed on today's employees, managers, and leaders. Online courses can continually and easily be refined to the most current and relevant practices. Administrators, in conjunction with faculty members, must integrate fair and consistent policies with regard to minimum standards and professional development guidelines for all faculty members who wish to integrate cyberspace technology to enhance student learning. Furthermore, equitable compensation strategies must be established for online educators since they do more work and must constantly stay abreast of new technologies needed to keep up with the cyberspace generation of students. Online students can encounter some of the most exciting, enriching course work available anywhere in education today... courses designed to challenge critical thinking skills... to widen perspectives on traditional business practices, and to foster an entrepreneurial spirit due to the unique skills of the individual faculty who can reside anywhere in the world while teaching courses online.

No matter the program or format, each program should utilize all the tools technology and management have to offer, giving students an unprecedented opportunity to acquire skills that will enrich their knowledge base and leadership abilities, while learning to add value to their company and to their lives.

\section{References}

1. Barnes, B. and Blackwell, C. (2004). Taking Business Training Online: Lessons from Academe. Journal of Applied Management and Entrepreneurship. Volume 9. Number 1. January Issue.

2. Debreceny, R. (1999) Outcomes assessment: The accreditation process. Available: http://www.lgc.peachnet.edu/sacs.html [November 19, 1999].

3. $\quad$ Eisner, Susan (2004). "Teaching Generation Y: Three Initiatives." Presented at the Teaching and Learning Conference (TLC). Orlando, Florida. January 5-9.

4. $\quad$ Gubernick, L. \& Ebeling, A. (1997). I Got My Degree Through E-Mail. Forbes: Pages 84-92. June 16.

5. Huizenga School, 2003. Retrieved in November 10, 2003 from the following URL: (http://www.huizenga.nova.edu).

6. Mujtaba, B. \& Mujtaba, L. (2004). "Creating a Healthy Learning Environment for Student Success in the Classroom.” The Internet TESL Journal. Vol. X, No. 2, February 2004. The article can be retrieved via the following URL link: http://iteslj.org/ or: http://iteslj.org/Articles/Mujtaba-Environment.html. 
7. Mujtaba, B.; Preziosi, R.; \& Mujtaba, L. (April 2004). "Adult Learning, Assessment, And the Extraordinary Teacher." Journal of College Teaching and Learning. Volume 1, Number 4. Pages 29-37. ISSN: 1544-0389. Western Academic Press.

8. Stone Soup Legend, 2003. The Stone Soup Legend. Retrieved November $10^{\text {th }} 2003$ from the following URL: http://www.kousi.gr.jp/kousi/syoukai/hp-siryou/stone-soup.html

Notes 
Notes 